\title{
Heart Failure with Preserved Ejection Fraction and Cardiac Amyloidosis: Implications for Treatment
}

\author{
Luiz Claudio Danzmann, ${ }^{1,2}$ [D João Ricardo Cambruzzi Zimmer, ${ }^{1}$ Anna Paula Tscheika ${ }^{2,3}$ \\ Universidade Luterana do Brasil (ULBRA), ${ }^{1}$ Canoas, RS - Brazil \\ Hospital São Lucas da PUC-RS, ${ }^{2}$ Porto Alegre, RS - Brazil \\ Hospital Universitário de Canoas, ${ }^{3} R S-$ Brazil
}

\begin{abstract}
Heart failure with preserved ejection fraction (HFpEF) is a syndrome with multiple etiologies and varied phenotypic manifestations. Amyloidosis is a systemic disease that frequently affects the myocardium, and it may represent a specific etiology of HFpEF. The treatment of HFpEF associated with amyloidosis is not based on specific evidence, and the risk of hypotension as an adverse effect of pharmacological management is always a concern. In this context, this review addresses some strategies for controlling circulatory congestion, arrhythmias, cardiac conduction disorders, valvular heart diseases, and treatment of the specific type of amyloidosis based on available evidence as well as the latest recommendations and guidelines for managing cardiac amyloidosis.
\end{abstract}

\section{Introduction}

Heart failure with preserved ejection fraction (HFpEF) is a syndrome with a potentially underestimated prevalence, and it accounts more than half of the population with heart failure (HF), when assessed in primary health care units. ${ }^{1} \mathrm{HFpEF}$ is induced by multiple coexisting morbidities, mainly of noncardiac origin, leading to systemic inflammation, increased oxidative stress, endothelial dysfunction, and biochemical signaling that determines hypertrophy and decreased elasticity of the cardiac myocyte, in addition to some degree of interstitial fibrosis. The functional result is an increase in ventricular filling pressures, especially during exertion, culminating in symptoms and signs of HF. ${ }^{2}$ Some systemic diseases can specifically alter the cardiac extracellular matrix, which is the case of cardiac amyloidosis (CA). This infiltrative cardiomyopathy most strongly impacts myocardial stiffening due to tissue deposition of insoluble fibrillary proteins in different tissues, including the myocardium, valves, and cardiac conduction tissue. The following amyloidogenic proteins may affect the heart: immunoglobulin heavy chain proteins; immunoglobulin

\section{Keywords}

Keywords: Heart Failure; Therapeutics; Amyloidosis.

Mailing Address: Luiz Claudio Danzmann •

ORCID: 0000-0002-5774-2780

Avenida Ipiranga 6690/402. Postal Code: 96610-000, Jardim Botânico, Porto Alegre, RS - Brazil.

E-mail: luiz.danzmann@gmail.com

Manuscript received October 11, 2021, revised manuscript October 18 , 2021, accepted October 18, 2021.

DOI: https://doi.org/10.36660/abchf.20210033 light chain proteins (AL); and those related to transthyretin (ATTR), to amyloid A, and to apolipoprotein A1. In practice, pathophysiological models due to the AL and ATTR types represent more than $90 \%$ of cases of CA. ${ }^{3}$

The clinical condition of HF arises from an inadequate cardiac response to the need for increased cardiac output, linked to depressed systolic volume due to inadequate left ventricular pressure-volume ratio, to the chronotropic response compromised by sinus frequency, or to atrioventricular conduction blocks. Arrhythmic complications, which are related mainly to atrial fibrillation and to the potential thromboembolic impairment in this condition, but also to ventricular arrhythmias, occur in the more advanced stages of the disease, when systolic dysfunction is already installed. Parallel to myocardial changes, postural hypotension and syncope may occur due to dysautonomia related to neuronal amyloid infiltration, while aortic valve stenosis secondary to amyoloidosis may severely compromise a condition of HFpEF or represent a clinical syndrome of severe aortic stenosis. ${ }^{4,5}$

The bases of treatment for HFpEF associated with cardiac amyloidosis

Recommendations for treatment of HFpEF in patients with $\mathrm{CA}$ are not based on data from randomized clinical trials (RCT), but on observational studies with few participants, involving more traditional drugs, such as beta-blockers, digitalis, diuretics, angiotensin-converting enzyme inhibitors (ACEI) and angiotensin II receptor blockers (ARB). Medications more recently introduced as options for managing HFpEF, such as angiotensin receptor-neprilysin inhibitors, and sodiumglucose cotransporter 2 inhibitors have not yet been studied in combined HFpEF and CA. Arrhythmic complications, in terms of both atrial fibrillation and atrioventricular blocks must also be addressed, because, from the pathological point of view, patients with CA, even without loss of left ventricular ejection fraction (LVEF), have difficulty maintaining cardiac output or increasing it during exercise, and conventional HF treatment strategies that have an impact on reduced heart rate, preload, and afterload, can cause symptomatic hypoperfusion. ${ }^{6}$ Appropriate treatment of amyloidosis should be guided according to diagnosis of the two important phenotypic groups, AL or ATTR amyloidosis (Figure 1).

\section{Diuretics}

Diuretic treatment for all HF phenotypes is based on principles of clinical plausibility, rather than on placebocontrolled RCTs, for obvious reasons. One piece of evidence available for management of patients with HFpEF, although 


\section{Review Article}

it was not designed for patients with CA exclusively, comes from the Hong Kong study. ${ }^{7}$ That trial tested treatment with diuretics (loop or thiazide) alone or associated with ACEI or ARB in relation to outcomes of quality of life, functional capacity, and rates of cardiac function in a population of 150 participants with HF, in New York Heart Association (NYHA) class II to IV, and LVEF > 45\%. The study was not placebo controlled. They evaluated the outcomes of HF symptoms and the Minnesota quality of life score $(-46 \%$, $p<0.01)$ in the comparison between 0 and 52 weeks of follow-up. Association with ramipril or irbesartan did not add additional clinical benefits.

The effect of the diuretic can also be verified when its use is guided by the degree of circulatory congestion with invasive pulmonary pressure devices. The CHAMPION study, ${ }^{8}$ using a pressure-sensing device implanted in the pulmonary artery, tested its effectiveness as a guide for the use of diuretics. The population was not specifically composed of patients with HFpEF and CA, but 23\% of participants had LVEF $\geq 40 \%$. Patients with device-guided diuretic treatment had 28\% lower hospital admission rates for HF (RR: $0.72,95 \% \mathrm{Cl}: 0.60$ to $0.85, \mathrm{p}=0.0002$ ), demonstrating not only the potential usefulness of this type of device, but also the clinical benefit of effective decongestion.

The 2021 Update to the Brazilian Guidelines on Heart Failure ${ }^{9}$ classifies diuretic therapy as a class I recommendation with level of evidence B for patients with HFpEF with evidence of clinical congestion, but these drugs should be used cautiously due to the possibility of hypotension, ${ }^{10}$ especially in patients with neurological dysfunction due to polyneuropathy, whose diuretic doses must be appropriately adjusted to avoid syncope.

\section{Mineralocorticoid-receptor antagonists}

This is one of the most investigated drug classes in populations with HFpEF. The TOPCAT study ${ }^{11}$ allocated a population of 3,445 patients with HF and LVEF $\geq 45 \%$, randomized to spironolactone versus placebo. ${ }^{11} \mathrm{~A}$ reduction in the primary endpoint composed of total cardiovascular mortality, sudden death, or hospitalization due to HF was not achieved, but the isolated secondary endpoint of HF hospitalization was reduced by $14 \%$. Nevertheless, spironolactone appears to have a more consistent effect in the most congested patients, as a post hoc analysis testing the population with elevated natriuretic peptides found a $35 \%$ reduction in the primary composite endpoint. In patients with CA, there are no specific studies, and, even if this class of drugs has reached a class Ila recommendation, according to the current Brazilian Guidelines on Heart Failure, ${ }^{12}$ these drugs should be used sparingly, on account of the potential hypotensive effect due to relative hypovolemia in this group. In a recent position statement by the Brazilian Society of Cardiology, mineralocorticoid-

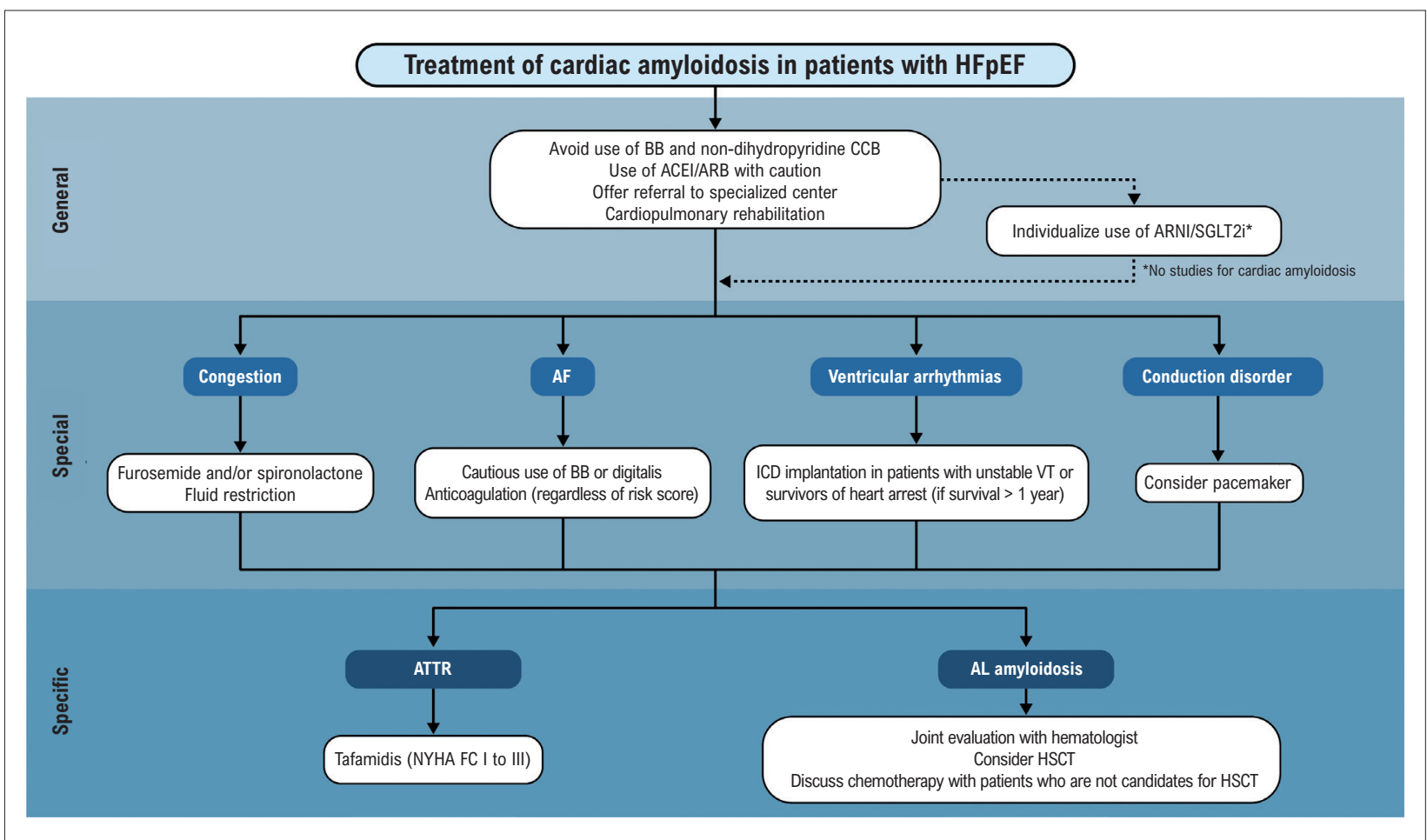

Figure 1 - Treatment of cardiac amyloidosis in patients with HFpEF. ACEl: angiotensin-converting enzyme inhibitors; AF: atrial fibrillation; AL: light-chain; ARB: angiotensin II receptor blockers; ARNI: angiotensin receptor-neprilysin inhibitors; ATTR: transthyretin amyloidosis; BB: beta-blockers; CCB: calcium channel blockers; HFpEF: heart failure with preserved ejection fraction; HSCT: hematopoietic stem cell transplantation; ICD: implantable cardioverter-defibrillator; NYHA FC: New York Heart Association functional class; SGLT2i: sodium-glucose cotransporter 2 inhibitors; VT: ventricular tachycardia 
receptor antagonists have been recommended for patients with congestion, $\mathrm{HFpEF}$, and $\mathrm{CA}$, provided that there is monitoring for eventual hypotensive manifestations. ${ }^{13}$

\section{Angiotensin II receptor blockers}

The CHARM-Preserved Trial allocated participants with HF, functional class II and III, and LVEF $>40 \%$, testing candesartan versus placebo. The results demonstrated a reduction in the number of hospitalizations due to HF. In the Brazilian Guidelines on Heart Failure, ${ }^{12}$ ARB in HFpEF is a class IIb recommendation with level of evidence $B$; however, this does not consider cases of amyloidosis. In relation to $\mathrm{ACEI}$, strictly speaking, there have not been any RCTs that have demonstrated benefit versus placebo in patients with HFpEF, and the guidelines do not include recommendations regarding this drug class for this group of patients. ${ }^{14} \mathrm{~A}$ recent position paper on CA by the European Society of Cardiology ${ }^{15}$ recommends avoiding ARB and $\mathrm{ACEl}$, due to their hypotensive potential in cases of $\mathrm{HF}$, in general. However, this recommendation should be viewed with caution, as many patients with HFpEF and amyloidosis may present with hypertension.

\section{Sacubitril/valsartan}

The best evidence for the use of this medication in HFpEF comes from the PARAGON-HF Trial, ${ }^{16}$ which included 4,796 participants with LVEF $\geq 45 \%$, elevated natriuretic peptides, and NYHA functional class II to IV. The results showed no benefits in terms of cardiovascular mortality and/or hospitalization for HF. However, in a prespecified analysis, a reduction in this composite outcome was observed in female participants and in those of both sexes who had LVEF $<57 \%$. These results suggest that sacubitril-valsartan could be an alternative for populations with HFpEF, symptoms that are difficult to control, and LVEF below $57 \%$. The use of this drug has not been tested in the context of CA, and it is necessary to be very cautious regarding the potential reduction of left ventricular preload and postload and eventual hypotensive effects. This medication is currently only recommended for patients with HF with slightly reduced LVEF, in the 2021 Update to the Brazilian Guidelines on Heart Failure. ${ }^{9}$

\section{Sodium-glucose cotransporter inhibitors}

The SOLOIST-WHF RCT recruited a population of patients with type 2 diabetes who had recently been hospitalized due to HF, testing sotagliflozin versus placebo, finding a significant reduction in the outcome of cardiovascular death and hospitalization due to worsening $\mathrm{HF}$ in patients with both reduced LVEF and preserved LVEF (RR $=0.67,95 \% \mathrm{Cl}, 0.52$ to $0.85, \mathrm{p}<0.001)$. The EMPEROR Preserved placebo-controlled RCT ${ }^{17}$ allocated 5,988 participants with signs and symptoms of HF, with patterns of heart failure with slightly reduced ejection fraction and HFpEF (LVEF > 40\%) and high serum levels of natriuretic peptides. The results of the study demonstrated a $25 \%$ reduction in the relative risk for the combined primary endpoint of cardiovascular death and hospitalization due to $\mathrm{HF}$, making it the first study to demonstrate a reduction in the primary endpoint in populations with HF with LVEF $>40 \%$. This class of drugs represents a potential therapeutic resource in HFpEF associated with CA, as it does not promote hypovolemia, bradycardia, or exacerbated hypotension; however, patients' volume status and blood pressure should be monitored during use.

\section{Beta-adrenergic blockers and calcium channel blockers}

Regarding patients with HFpEF, beta-blockers are only recommended for the treatment of angina pectoris in patients with HFpEF associated with the ischemic phenotype or for heart rate control in the event of atrial fibrillation. ${ }^{12}$ In the context of CA, beta-blockers and non-dihydropyridine calcium channel blockers are generally not well tolerated, due to their negative influence on chronotropism. Furthermore, non-dihydropyridine calcium channel blockers should be avoided in patients with AL-CA as they bind to amyloid fibrils, which can result in advanced heart blocks. ${ }^{18}$

\section{Digoxin}

In patients with atrial fibrillation and high ventricular response, digoxin is always remembered as a therapeutic alternative. However, an in vitro study has demonstrated that isolated amyloid fibrils bind to digoxin with an important degree of affinity. ${ }^{19}$ This interaction may play some role in the sensitivity to digoxin observed in some patients with $\mathrm{CA}$, and this selective binding of digoxin to amyloid fibrils may increase the severity of myocardial disorders previously attributed to fibrillar amyloid deposits. In general, therefore, great caution is recommended when administering digoxin to patients with CA.

\section{Atrial fibrillation and prevention of embolic phenomena}

The management of atrial fibrillation by heart rate control should be carried out with monitoring of possible excessive bradycardia by commonly used agents, due to the aforementioned reasons. Radioablation for this arrhythmia seems to be feasible, and it may be an interesting alternative when performed early in CA. ${ }^{20,21}$

Anticoagulation has been indicated for CA with atrial fibrillation regardless of the risk score for thromboembolism, given that atrial amyloid infiltration significantly reduces atrial contractility and increases the possible appearance of thrombi, especially in AL-CA. ${ }^{13}$ Anticoagulation in patients in sinus rhythm has not been well established, but it can be considered in specific cases of decreased contractility or cardiac deformation, especially in cases of AL-CA.

\section{Ventricular arrhythmias}

Non-sustained tachycardia is the most frequently detected ventricular arrhythmia on electrocardiographic monitoring, in cases of $\mathrm{AL}-\mathrm{CA},{ }^{22}$ and, in this context, an implanted defibrillator may be an option, even without systolic ventricular dysfunction. However, implanting these devices for primary prevention per se can be ineffective, given that most events have pulseless electrical activity. ${ }^{23}$ 


\section{Review Article}

Thus, the best evidence is in favor of early detection, when it is possible to identify arrhythmias that can potentially be treated by devices. ${ }^{24}$

\section{Cardiac conduction blocks}

Blockages, especially atrioventricular blocks, are frequent in amyloidosis. Implantation of artificial stimulation is effective and in following with the contemporary recommendations for the disease. ${ }^{25}$

\section{Specific treatment of amyloidosis}

Treatment should follow diagnosis of the phenotype of CA. Once AL-CA has been diagnosed, it becomes urgent to activate the hematology team in order to initiate treatment with antineoplastic agents and/or autologous stem cell transplantation. ${ }^{13}$

\section{Treatment of ATTR-CA}

The following potential treatments exist for CA caused by TTR: a- TTR tetramer stabilizers; b- inhibitors of hepatic TTR synthesis; C- degradation and resorption of deposited amyloid fibrils, and d- liver transplantation. ${ }^{13}$

Tafamidis is a tetramer stabilizer and the only drug that has been tested in a multicenter RCT, the ATTR-ACT study. ${ }^{26}$ Patients were not selected by ejection fraction, but rather by NYHA functional class between I and III and high BNP. The groups that received tafamidis 80 and $20 \mathrm{mg}$ were analyzed together, and the results indicated a statistically significant $30 \%$ reduction in the relative risk of all-cause mortality $(\mathrm{RR}=0.70[95 \% \mathrm{Cl}: 0.51$ to 0,96$])$, as well as a $32 \%$ reduction in cardiovascular hospitalizations $(\mathrm{RR}=$ 0.68 [95\% Cl: 0.56 to 0.81]). Subsequently, a long-term extension of the same study demonstrated that the sample that received $80 \mathrm{mg}$ of tafamidis had an additional 30\%

\section{References}

1. Jorge $\mathrm{AL}$, Rosa ML, Martins WA, Correia DM, Fernandes LC, Costa JA, et al. The Prevalence of Stages of Heart Failure in Primary Care: A Population-Based Study. J Card Fail. 2016;22(2):153-7. doi: 10.1016/j. cardfail.2015.10.017.

2. Paulus WJ, Tschöpe C. A Novel Paradigm for Heart Failure with Preserved Ejection Fraction: Comorbidities Drive Myocardial Dysfunction and Remodeling Through Coronary Microvascular Endothelial Inflammation. J Am Coll Cardiol. 2013;62(4):263-71. doi: 10.1016/j.jacc.2013.02.092 1.

3. Falk RH, Alexander KM, Liao R, Dorbala S. AL (Light-Chain) Cardiac Amyloidosis: A Review of Diagnosis and Therapy. J Am Coll Cardiol. 2016;68(12):1323-41. doi: 10.1016/j.jacc.2016.06.053.

4. González-López E, Gallego-Delgado M, Guzzo-Merello G, Haro-Del Moral FJ, Cobo-Marcos M, Robles C, et al. Wild-Type Transthyretin Amyloidosis as a Cause of Heart Failure with Preserved Ejection Fraction. Eur Heart J. 2015;36(38):2585-94. doi: 10.1093/eurheartj/ehv338.

5. Witteles RM, Bokhari S, Damy T, Elliott PM, Falk RH, Fine NM, et al. Screening for Transthyretin Amyloid Cardiomyopathy in Everyday Practice. JACC Heart Fail. 2019; 7(8):709-16. doi: 10.1016/j.jchf.2019.04.010. decrease in relative risk of the outcome of mortality $(R R=$ $0.70,95 \% \mathrm{Cl}: 0.5$ to $0.97, \mathrm{p}=0.037) .{ }^{27}$

\section{Final considerations}

The association of HFpEF and CA is based on the plausibility of treating circulatory congestion, heart rhythm, and associated morbidities, but, above all, treating amyloidosis itself. Potentially hypotensive drugs must be used very cautiously and bradycardia-causing agents must be avoided.

\section{Author contributions}

Conception and design of the research:Danzmann LC. Acquisition of data: Danzmann LC, Tscheika AP, Zimmer JRC. Analysis and interpretation of the data:Danzmann LC, Tscheika AP, Zimmer JRC. Writing of the manuscript:Danzmann LC, Tscheika AP. Critical revision of the manuscript for intellectual content: Danzmann LC. Supervision / as the major investigador: Danzmann LC.

\section{Potential Conflict of Interest}

No potential conflict of interest relevant to this article was reported.

\section{Sources of Funding}

There were no external funding sources for this study.

\section{Study Association}

This study is not associated with any thesis or dissertation work.

\section{Ethics approval and consent to participate}

This article does not contain any studies with human participants or animals performed by any of the authors.

6. Castaño A, Drachman BM, Judge D, Maurer MS. Natural History and Therapy of TTR-Cardiac Amyloidosis: Emerging Disease-Modifying Therapies from Organ Transplantation to Stabilizer and Silencer Drugs. Heart Fail Rev. 2015;20(2):163-78. doi: 10.1007/s10741-014-9462-7.

7. Yip GW, Wang M, Wang T, Chan S, Fung JW, Yeung L, et al. The Hong Kong Diastolic Heart Failure Study: A Randomised Controlled Trial of Diuretics, Irbesartan and Ramipril on Quality of Life, Exercise Capacity, Left Ventricular Global and Regional Function in Heart Failure with a Normal Ejection Fraction. Heart. 2008;94(5):573-80. doi: 10.1136/ hrt.2007.117978.

8. Abraham WT, Adamson PB, Bourge RC, Aaron MF, Costanzo MR, Stevenson LW, et al. Wireless Pulmonary Artery Haemodynamic Monitoring in Chronic Heart Failure: A Randomised Controlled Trial. Lancet. 2011;377(9766):658-66. doi: 10.1016/S01406736(11)60101-3.

9. Marcondes-Braga FG, Moura LAZ, Issa VS, Vieira JL, Rohde LE, Simões $M V$, et al. Emerging Topics Update of the Brazilian Heart Failure Guideline - 2021. Arq Bras Cardiol. 2021;116(6):1174-212. doi: 10.36660/abc. 20210367 
10. Gertz MA, Dispenzieri A, Sher T. Pathophysiology and Treatment of Cardiac Amyloidosis. Nat Rev Cardiol. 2015;12(2):91-102. doi: 10.1038/ nrcardio.2014.165.

11. Pitt B, Pfeffer MA, Assmann SF, Boineau R, Anand IS, Claggett B, et al. Spironolactone for Heart Failure with Preserved Ejection Fraction. N Engl J Med. 2014;370(15):1383-92. doi: 10.1056/NEJMoa1313731.

12. Rohde LEP, Montera MW, Bocchi EA, Clausell NO, Albuquerque DC, Rassi S, et al. Diretriz Brasileira de Insuficiência Cardíaca Crônica e Aguda. Arq Bras Cardiol. 2018;111(3):436-539. doi: 10.5935/abc.20180190.

13. Simões MV, Fernandes F, Marcondes-Braga FG, Scheinberg P, Correia EB, Rohde LEP, et al. Position Statement on Diagnosis and Treatment of Cardiac Amyloidosis - 2021. Arq Bras Cardiol. 2021;117(3):561-98. doi: 10.36660/ abc.20210718.

14. McDonagh TA, Metra M, Adamo M, Gardner RS, Baumbach A, Böhm M et al. 2021 ESC Guidelines for the Diagnosis and Treatment of Acute and Chronic Heart Failure. Eur Heart J. 2021;42(36):3599-726. doi: 10.1093/ eurhearti/ehab368.

15. Garcia-Pavia P, Rapezzi C, Adler Y, Arad M, Basso C, Brucato A, et al. Diagnosis and Treatment of Cardiac Amyloidosis. A Position Statement of the European Society of Cardiology Working Group on Myocardial and Pericardial Diseases. Eur J Heart Fail. 2021;23(4):512-26. doi: 10.1002/ ejhf.2140.

16. Solomon SD, McMurray JJV, Anand IS, Ge J, Lam CSP, Maggioni AP, et al. Angiotensin-Neprilysin Inhibition in Heart Failure with Preserved Ejection Fraction. N Engl J Med. 2019;381(17):1609-20. doi: 10.1056/ NEJMoa1908655.

17. Anker SD, Butler J, Filippatos G, Ferreira JP, Bocchi E, Böhm M, et al Empagliflozin in Heart Failure with a Preserved Ejection Fraction. N Engl J Med. 2021;385(16):1451-61. doi: 10.1056/NEJMoa2107038.

18. Pollak A, Falk RH. Left Ventricular Systolic Dysfunction Precipitated by Verapamil in Cardiac Amyloidosis. Chest. 1993;104(2):618-20. doi: 10.1378/ chest.104.2.618.
19. Rubinow A, Skinner M, Cohen AS. Digoxin Sensitivity in Amyloid Cardiomyopathy. Circulation. 1981;63(6):1285-8. doi: 10.1161/01. cir.63.6.1285

20. Mints YY, Doros G, BerkJL, Connors LH, Ruberg FL. Features of Atrial Fibrillation in Wild-type Transthyretin Cardiac Amyloidosis: A Systematic Review and Clinical Experience. ESC Heart Fail. 2018;5(5):772-9. doi: 10.1002/ ehf2.12308.

21. Donnellan E, Wazni O, Kanj M, Elshazly MB, Hussein A, Baranowski B, et al. Atrial Fibrillation Ablation in Patients with Transthyretin Cardiac Amyloidosis. Europace. 2020;22(2):259-64. doi: 10.1093/europace/euz314.

22. Palladini G, Malamani G, Cò F, Pistorio A, Recusani F, Anesi E, et al. Holter Monitoring in AL Amyloidosis: Prognostic Implications. Pacing Clin Electrophysiol. 2001;24(8):1228-33. doi: 10.1046/j.1460-9592.2001.01228.x.

23. Sayed RH, Rogers D, Khan F, Wechalekar AD, Lachmann HJ, Fontana M, et al. A Study of Implanted Cardiac Rhythm Recorders in Advanced Cardiac AL Amyloidosis. Eur Heart J. 2015;36(18):1098-105. doi: 10.1093/eurhearti/ ehu506.

24. Giancaterino S, Urey MA, Darden D, Hsu JC. Management of Arrhythmias in Cardiac Amyloidosis. JACC Clin Electrophysiol. 2020;6(4):351-61. doi: 10.1016/j.jacep.2020.01.004.

25. Topilsky Y, Pereira NL, Shah DK, Boilson B, Schirger JA, Kushwaha SS, et al. Left Ventricular Assist Device Therapy in Patients with Restrictive and Hypertrophic Cardiomyopathy. Circ Heart Fail. 2011;4(3):266-75. doi: 10.1161/CIRCHEARTFAILURE.110.959288.

26. Maurer MS, SchwartzJH, Gundapaneni B, Elliott PM, Merlini G, WaddingtonCruz M, et al. Tafamidis Treatment for Patients with Transthyretin Amyloid Cardiomyopathy. N Engl J Med. 2018;379(11):1007-16. doi: 10.1056/ NEJMoa1805689.

27. Damy T, Garcia-Pavia P, Hanna M, Judge DP, Merlini G, Gundapaneni B, et al. Efficacy and Safety of Tafamidis Doses in the Tafamidis in Transthyretin Cardiomyopathy Clinical Trial (ATTR-ACT) and Long-Term Extension Study. Eur Heart Fail. 2021;23(2):277-85. doi: 10.1002/ejhf.2027. 